\title{
EFEKTIVITAS MANAJEMEN PEMBELAJARAN KARAKTER BERBASIS FINANCIAL LITERASI DI SEKOLAH DASAR
}

\author{
Sri Utaminingsih 1), Eka Zuliana 2) \\ Program Studi Pendidikan Guru SD, Universitas Muria Kudus, Indonesia \\ sri.utaminingsih@umk.ac.id, eka.zuliana@umk.ac.id
}

\begin{abstract}
The purpose of this research is to know the level of financial literacy learning model effectivity for building quality character of sekkah student base The effectivity levels of the models will be used to determine whether the model can be used as best practical or not. Number of population of 272 and it all made as the respondents. Data analysis using t-test and tools to validate using the kendall and spearman, while for reliability using cronbach alpha as its parameters. The results showed the existence of level models effectivities at the level of significance of 1\%, the components of the planning, the implementation and evaluation has an impact on the success of the formation of nonkonsumerisme character and spirit of entrepreneurship.
\end{abstract}

Keywords: Financial Literacy, Quality, Character, Primary School

\begin{abstract}
Abstrak
Tujuan penelitian ini adalah untuk mengetahui tingkat keefektifan model manajeme pembelajaran financial literasi untuk membangun kualitas karakter siswa sekolah dasar. Metode penelitian yang digunakan adalah penelitian pengembangan melalui pengembangan pembelajaran berbasis financial literacy. Tingkat kefektifan model akan dapat digunakan untuk menentukan apakah model bisa dijadikan best praktis atau tidak. Jumlah Populasi sebanyak 272 dan semuanya dijadikan responden. Analisa data dengan menggunakan uji t dan alat untuk memvalidasi menggunakan Kendall dan Spearman, sementara untuk realibilitas menggunakan alpha cronbach sebagai parameternya. Hasil penelitian menunjukka model manajemen pembelajaran finacial literasi untuk membangun kualitas karakter siswa cukup efektif pada taraf signifikansi $1 \%$, komponen perencanaan, pelaksanaan dan evaluasi memiliki pengaruh terhadap keberhasilan pembentukan karakter nonkonsumerisme dan jiwa wirausaha.
\end{abstract}

Kata Kunci: manajemen pembelajaran, financial literasi, karakter

\section{PENDAHULUAN}

Perilaku konsumtif saat ini merupakan suatu fenomena yang melanda bangsa Indonesia, juga dikalangan anak-anak. Saat ini anak dihadapkan pada perilaku materialisme yang menganggap bahwa seolah-olah materi dan uang adalah segala-galanya. Hal ini dapat mengancam terkikisnya nilai-nilai kehidupan manusia, meruntuhkan nilai-nilai kesantunan, dan prilaku anak yang cenderung negatif sehingga berpengaruh pada karakter anak.

Pendidikan karakter penting untuk dilakukan sejak dini, baik oleh keluarga sekolah maupun di masyarakat sehingga anak bisa berkembang optimal dan tumbuh menjadi pribadi yang berkarakter. Proses pendidikan karakter merupakan keseluruhan proses pendidikan yang dialami anak sebagai pengalaman pembentukan kepribadian melalui memahami nilai-nilai dan keutamaannya. (Rachman, 2011:27). Menurut Megawangi (2003), terdapat sembilan pilar karakter yang penting ditanamkan pada anak, antara lain 1) cinta tanah air; 2). Tanggungjawab, kemandirian, kedisiplinan; 3). Kejujuran; 4) hormat dan santun; 5). peduli dan kerjasama; 6 percaya diri, kreatif, kerja keras, pantang menyeraha; 7). keadilan dan kepimpinan; 8) baik dan rendah hati; 9). tolereansi, cinta damai dan persatuan. 
Pembentukan karakter anak pada tingkat sekolah dasar dapat dilakukan dengan berbagai cara dan materi. Salah satu materi yang bisa dikembangkan untuk membangun karakter anak adalah pentingnya pembelajaran tentang melek keuangan (finacial literacy) yang merupakan pembelajaran life skill yang akan diperlukan bagi kehidupan masa depan anak.

Di sisi lain pembelajaran karakter merupakan merupakan proses adaptasi menurut Piaget dalam Nurhadi ( 2004), ada 4 konsep dasar dalam adaptasi yaitu: intellectual scheme, assimilation, accomodation, and equilibrium. Adaptasi pada intelllectual scheme memberikan arti pada perlunya pengetahuan yang mampu mengubah mindset pada siswa, hal ini berarti sistem pembelajaran diharapkan dapat memeberikan perubahan paradigma, yang disesuaikan dengan adanya perubahan lingkungan seperti perubahan teknologi, perubahan sosial dan lainnya. Jika proses perubahan pola pemikiran dapat dicapai maka siswa akan mengasimilasikan konsep pemikiran yang mereka terima, dan konsep tersebut akan diakomodasikan dalam perilaku yang selanjutnya memberikan keseimbangan dalam menjustifikasi pemikiran, perilaku dan aplikasi sikap.

Penanaman rasa tanggung jawab pada bidang ekonomi sejak dini dapat memberikan karakter bagi anak agar tidak bersikap hidup boros, konsumeris dan lebih jauh, pandai dalam mengelola keuangannya, dan berdampak pada kesejahteraan ekonominya. Pengembangan pembelajaran karakter menurut Lickona (1992) harus menyentuh 3 aspek yakni: moral knowing, moral feeling, dan moral behavior. Pemahaman dan pengetahuan moral merupakan landasan awal untuk mengerti yang akan dijadikan pertimbangan dalam pemikiran tentang baik dan buruk, sedangkan moral feeling merupakan perasaan menimbang akan memberikan justifikasi pada pemahaman moral dan selanjutnya akan dilakukan dan menjadi sikap dan perilaku (behavior). Demikian pula dalam pembelajaran karakter berbasis finacial literasi, penggunaan uang tidak hanya sekedar pemahaman pengetahuan, tetapi harus menjadi sikap dan perilaku.

Dua komponen utama yang diukur dalam penelitian ini adalah sikap nonkonsumtif (nonkonsumerisme) dan jiwa wirausaha siswa sebagai wujud upaya mempertahnkan eksistensi kehidupan. Jiwa non konsumerisme mencakup komponen pemenuhan keinginan, jangkauan atau kemampuan membeli, produktifitas barang yang dibeli dan dampak social yang ditimbulkan dari pembelian produk atau jasa yang dibeli. Sedangkan komponen jiwa wirausaha mencakup kepercayaan diri, inisiatif, kemauan mengambil resiko, jiwa kepemimpinan dan motivasi untuk berprestasi.

Pada pembelajaran melek keuangan menurut Abbeson (2008:35-46), memiliki tujuan agar siswa menjadi cerdas dalam membuat pilihan yang bijaksana dalam mengelola keuangannnya. Pembelajaran pemahaman literasi keuangan sangat berkaitan erat dengan kemampuan mengelola keuangan di masa depan, kemanfaatamya yaitu mampu memperkuat stabilitas keuangan bagi individu, keluarga, dan seluruh komunitas. ( Senduk: 2002; Adam, 2013) Hasil Penelitian Cude et.al (2006) menunjukkan pembelajaran keuangan pada siswa yang diajarkan oleh orang tua dan di sekolah memiliki pengaruh positif pada penggunaan uang yang diberikan pada siswa, yang mana menurunkan tingkat pengeluaran mereka sampai $70 \%$, dan otomatis meningkatkan tabungan mereka. Fungsi uang memiliki kemanfaatan yang lebih dalam dari sekedar untuk alat membeli. Uang bisa digandakan, dipekerjakan, dan merupakan pendukung utama untuk meraih cita - cita kesejahteraan hidup.

Tujuan dari penelitian ini adalah untuk mengukur tingkat efektivitas model pembelajaran karakter berbasis finacial literasi yang telah diformulasikan dan dikembangkan dalam penelitian terdahulu, jika memiliki efektivitas maka model yang telah diukur akan dijadikan 
best practices untuk pembelajaran karakter berbasis literasi keuangan di sekolah dasar. Tujan tersebut mengantarkan pada pertanyaan penelitian: Apakah model pembelajaran finansial literasi di tingkat SD untuk membangun karakter non konsumerisme dan jiwa wirausaha merupakan model efektif?

Pengembangan model yang telah diformulasikan oleh peneliti adalah sebagai model yang dikembangkan untuk melaksanakan pembelajaran karakter berbasis financial literasi untuk tingkat sekolah dasar dalam membangun karakter nonkunsumerisme dan jiwa wirausaha yang mencakup tiga komponen yaitu: input, proses, dan output. Merujuk dari diskusi teori dan berbagai penelitian maka model harus memiliki kriteria sebagai berikut: 1). Model pembelajaran harus merupakan bagian dari sistem pembelajaran yang memiliki komponen utama input, proses, output dan outcome. 2). Model pembelajaran karakter memiliki tujuan untuk memberikan soft skill dalam koridor life skill oleh karena itu harus membentuk moral pada tingkat pengetahuan, afektif, dan psikomotor.3). Sebagai model pembelajaran yang inovatif maka prinsip PAIKEM harus mendasari model pembelajaran ini, hal ini sesuai dengan tingkat pertumbuhan siswa didik di Sekolah Dasar, yang masih lekat dengan suasana bermain dan menyenangkan. 4). Model pembelajaran financial literasi untuk sekolah dasar merupakan pemahaman tentang fungsi dan kegunaan uang serta motivasi dalam menggunakan dan memiliki uang, yang mana akan memberikan pemahaman ekonomi dalam batasan sesuai prinsip ekonomi, motive ekonomi dan melakukan tindakan ekonomis. 5). Model jika diimplementasikan harus memberikan perubahan karakter pada siswa didik.

\section{METODE}

Penelitian ini adalah untuk mengukur hasil temuan model, oleh karena itu penelitian ini menggunakan jenis penelitian kuantatif dengan desain penelitian pengembangan. Pada saat pengembangan model menggunakan pendekatan kualitatif. Pengukuran efektivitas model biasanya dengan membandingkan hasil pretest dan post test. Untuk uji efektivitas dengan menggunakan uji t dan uji $\mathrm{F}$, data dikumpulkan melalui quiz dan angket.

Populasi dari penelittian ini adalah sekolah dasar di wilayah Kabupaten Kudus dengan akreditasi A sebanyak 6 sekolah. Jumlah populasi sebanyak 272 siswa, dan penelitian ini merupakan penelitian populasi sehingga semua jumlah populasi dijadikan responden. Jenis data dalam penelitian ini dibedakan menjadi dua, yaitu data primer dan data sekunder. Data primer yang diperoleh dalam bentuk verbal atau kata-kata dan perilaku subyek (informan) yang berkaitan dengan penelitian. Sedangkan data sekunder bersumber dari dokumen-dokumen, foto-foto, rekaman dan benda-benda yang digunakan sebagai pelengkap data primer. Data-data tersebut diperoleh dari subyek penelitian. Penetapan informan sebagai sumber data menggunakan tehnik purposive sampling atau sampel bertujuan dengan pertimbangan tertentu antara lain yaitu mengajar kelas IV dan memahamim konsep financial literacy. Pengumpulan data dalam penelitian ini menggunakan teknik : (1) wawancara mendalam; (2) observasi; (3) Focus Group Discussion; dan (4) studi dokumentasi; penyebaran angket (quis). Penelitian untuk menguji efektivitas dengan menggunakan metode kuantitatif yaitu dengan menggunakan uji t dan uji f untuk menilai efektivitas model. Untuk mengukur efektivitas dari penggunaan model maka ada 3 variabel bebas yaitu Perencanaan, Pelaksanaan dan Evaluasi. Sedangkan variable terikatnya adalah kualitas hasil pembelajaran karakter nonkonsumerisme dan jiwa wirausaha.

Variabel penelitian ini adalah X1 (Perencanaan pembelajaran ) memiliki indicator identifikasi, perangkat pembelajaran, media pembelajaran. Variabel X2 ( pelaksanaan 
pembelajaran) memiliki indicator pembelajaran tematik, metode pembelajaran financial literacy. Variabel X3 (evaluasi pembelajaran) memiliki indicator penilaian otentik, personil, operasional, material. Variabel Y (kualitas pembelajaran karakter) dengan indicator karakter non konsumerisme dan karakter jiwa wirausaha. Analisa data dengan menggunakan uji t dan alat untuk memvalidasi menggunakan Kendall dan Spearman, sementara untuk realibilitas menggunakan alpha cronbach sebagai parameternya.

\section{HASIL DAN PEMBAHASAN}

Hasil penelitian menunjukan bahwa model manajemen pembelajaran karakter berbasis financial literasi di sekolah dasar belum menggunakan pendekatan manajemen yaitu perencanaan pembelajaran belum dilakukan secara sistematis oleh guru. Dalam proses pembelajaran juga belum menggunakan model-model pembelajaran atau metode yang menarik. Penelitian tersebut sejalan dengan penelitian yang telah dilakukan Sewell dan Hall (2003) bahwa pendidikan karakter sangat penting untuk dikembangkan dalam pelaksanaan kurikulum. Pengembangan kurikulum meliputi perencanaan dalam pembelajaran, yang meliputi silabus dan RPP. Walau hal ini agak berbeda dengan hasil penelitian Danik Astuti (2011) menyatakan bahwa pelaksanaan pengembangan karakter dapat dilaksanakan melalui proses pembelajaran dan di luar pembelajaran.

Dalam pembelajaran finacial litersi secara umum guru telah menyampaikan fungsi uang melalui teks/bacaan, memberikan nasehat tentang manfaat uang. Pengetahuan tentang uang sebagai alat jual beli diketahui semua anak, artinya anak tahu bahwa kalau tidak punya uang tidak bisa membeli sesuatu. Siswa juga tahu bahwa untuk mempunyai uang harus bekerja. Pada kurikulum 2013 pembelajaran finacial literasi untuk menumbuhkan jiwa nonkonsumerisme dan jiwa wirausaha dapat dimasukan pada semua tema pembelajaran yang ada.

Metode pembelajaran di sekolah juga belum menggunakan metode atau model pembelajaran inovatif. Hanya 2 sekolah yang mengajarkan fungsi uang dengan permainan. Permainan pertama sebagai sebagai penjual dan pembeli, kedua dengan monopoli. Pada model manajemen pembelajaran finacial literasi yang dikembangkan untuk membangun karakter menggunakan model pembelajaran problem based learning, hal ini karena memperhatikan karakteristikm materi pembelajaran dimana siswa perlu dihadapkan permasalahan-permasalahan sederhana terkait dengan keuangan dan pemecahannnya. Sedangkan dipilihnya project based learning dengan permainan seperti benda tiruan, benda asli, gambar, permainan tradisional. Dengan model pembelajaran tersebut anak akan memahami dan menemukan makna uang sehingga mempunyai moral knowing yang kokoh, selanjutnya moral feeling yang baik dan hal tersebut akan tercermin dalam sikap dan perilaku (behavior), hal ini memperkuat teori Lickona (1992). Lebih lanjut Lockona menyampaikan bahwa karakter yang baik mengandung tiga kompetensi yaitu mengetahui hal yang baik, ada keinginan terhadap hal baik dan melakukan hal baik. Terkait pembelajaran finacial litersi telah diajarkan hal baik tentang uang, keinginan siswa dalam mengelola uang seperti menabung, membeli kebutuhan sudah dipahami, hanya prakteknya yang masih sulit.

Model yang dikembangan ini merupakan model deskriptif, yang mana menurut Johanssen (1993) suatu proses atau sistem baik secara kuantitatif maupun kualitatif, model ini sering digunakan untuk tujuan saintifik dan teknologi. Oleh karena itu model pembejaran disusun pada gambar 1: 


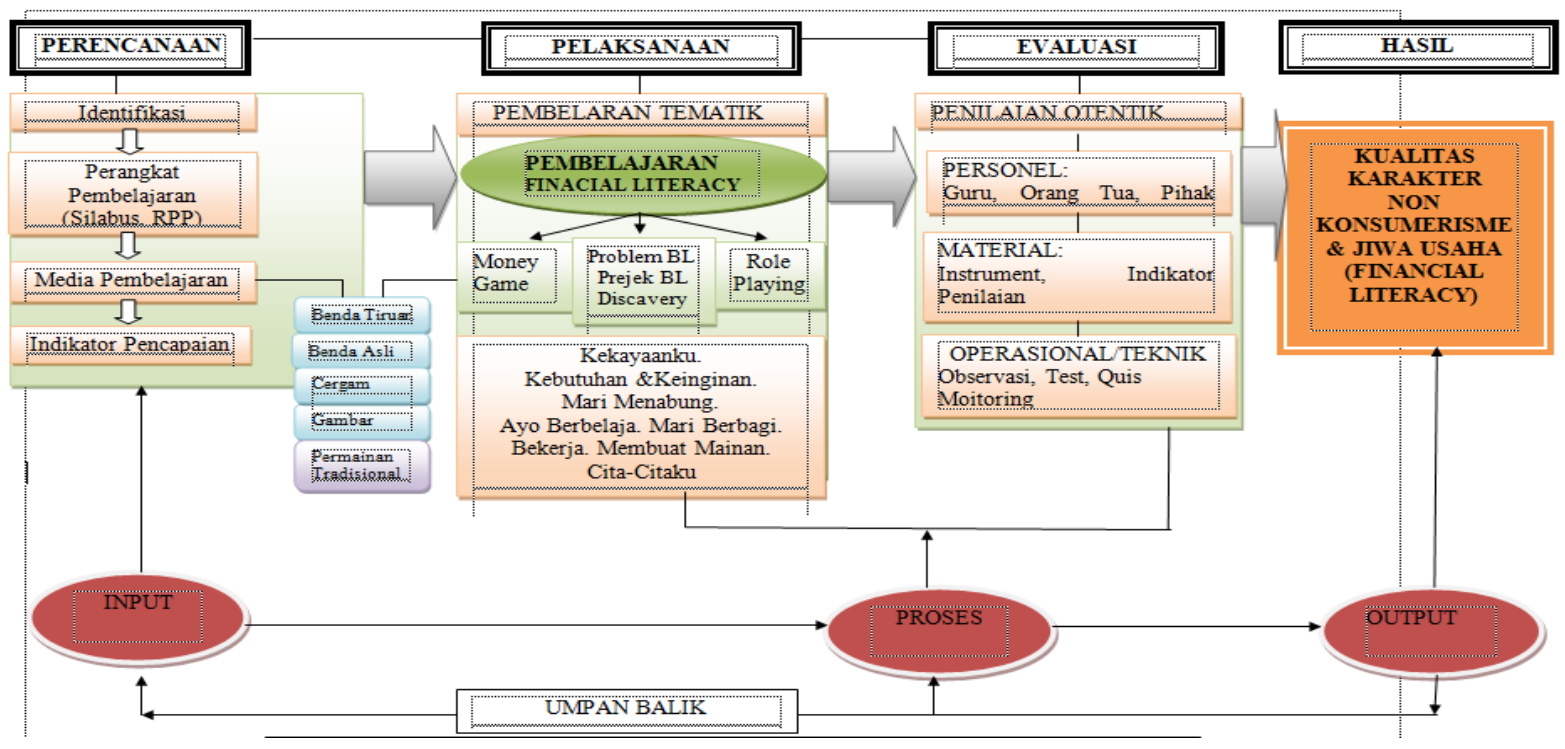

Gambar 1 Model Manajemen Pembelajaran Financial Literasi Untuk Membangun Karakter Nonkonsumerisme dan Jiwa Wirausaha

Pengembangan model manajemen pembelajaran karakter berbasis financial literasi tingkat sekolah dasar untuk membangun karakter nonkunsumerisme dan jiwa wirausaha yang akan diuji keefektivannya memiliki tiga komponen yaitu: input, proses, dan output.

1. Input: untuk input dalam pembelajaran maka disusun perencanaan yang mana dalam perencanaan memiliki sub komponen: Identifikasi Kebutuhan, Perangkat Pembelajaran, Media dan Bahan Ajar.

2. Proses: dalam proses ada dua komponen utama yaitu Pelaksanaan dan Evaluasi. Pelaksanaan adalah pelaksanaan pembelajaran, dari hasil kajian teori dinyatakan untuk tingkatan SD maka pembelajaran yang dilaksanakan harus lebh berorientasi pada joyful learning, dan hasil penelitian juga menunujukkan bahwa pembelajaran kelas IV kurikulum 2013 menggunakan model problem base learning dan juga berbagai permainan. Oleh karena itu dalam model ini maka metode pembelajaran yang digunakan adalah dengan menggunakan permainan (money game), role playing, cerita bergambar dan problem solving. Untuk Evaluasi kaidah pembelajaran pada tingkat SD masih memerlukan keterlibatan dari keluarga, lingkungan dan juga guru. Sesuai pendapat Suharsimi (2008) dalam evaluasi harus melihat adanya 3 hal utama yaitu personel, materi, dan operasional untuk itu sebagai model yang efektif harus mengikuti criteria tersebut. Dalam hal ini penilaian mencakup pada personel harus melibatkan guru dan orang tua serta lingkungan, pada materi perlu penentuan tolok ukur untuk penilaian maka ditentukan indicator penilaian, dan instrument. Sedangkan pada kegiatannnya penilaian bisa dengan melakukan tes, atau juga observasi dan monitoring.

3. Output: merupakan hasil yang diharapkan, dimana dalam output ini adalah tujuan pembelajaran financial literasi untuk meningkatkan karakter non konsumerisme dan jiwausaha. Hasil utama dari pembelajaran ini adalah 
kepandaian siswa dalam mengambil keputusan yang berkaitan dengan keuangan. Untuk dampak yang lebih luas (outcome) maka siswa akan mampu memilih penggunaan uang sesuai dengan kebutuhan, kepandaian dalam menggunakan uang secara cermat dan kreatif merupakan salah satu ciri dari jiwa kewirausahaan.

Hasil temuan pada penelitian pertama yang merupakan komponen model dan kemudian dikembangkan menjadi variable untuk menguji keberhasilan model perencanaan pembelajaran finacial literasi memiliki indicator identifikasi, perangkat pembelajaran, media pembelajaran dan bahan ajar, dimana dari hasil responden dapat dilihat pada tabel 1:

Tabel 1 . Distribusi Frekuensi Perencanaan Pembelajaran Finacial Literasi Indikator Jawaban

\begin{tabular}{rrrrrrr}
\cline { 2 - 7 } & $\mathbf{1}$ & $\mathbf{\%}$ & $\mathbf{2}$ & $\mathbf{\%}$ & $\mathbf{3}$ & $\mathbf{\%}$ \\
\hline $\begin{array}{r}\text { Identifikasi } \\
\text { Kebutuhan }\end{array}$ & 69 & 24 & 102 & 35.4 & 101 & 35.1 \\
\hline $\begin{array}{r}\text { Perangkat } \\
\text { Pembelajara }\end{array}$ & 50 & 17.4 & 118 & 41 & 104 & 36.1 \\
\hline $\begin{array}{r}\text { Media } \\
\text { Pembelajara }\end{array}$ & 75 & 26 & 102 & 35 & 95 & 33 \\
\hline
\end{tabular}

Data di atas menujukkan pada 3 elemen dasar perencanaan pembelajaran yaitu melaksanakan identifikasi kebutuhan cukup kurang dimana dapat dilihat hanya $24 \%$ yang melakukan, hal ini karena berbagai alasan diantaranya bahwa aspek karakter merupakan hidden curiculum yang belum menjadi tujuan utama dalam pembelajaran, pembelajaran masih berfokus aspek pengetahuan, sedangkan ragu ragu untuk melaksanakan cukup tinggi yaitu sebanyak 35,4 \% dan yang tidak melakukan juga $35 \%$. Untuk penyiapan perangkat pembelajaran hanya $17.4 \%$ yang menyiapkan, $41 \%$ kadang menyiapkan kadang tidak, dan yang tidak menyiapkan sama sekali sebanyak 36,2 \% dengan alasan sudah terbiasa mengajar jadi sudah tahu mana yang siswa yang berkarakter mana yang belum. Hal ini juga senada dengan temuan Nur Kholiq (2012) yaitu pentingnya upaya menanamkan pendidikan karakter yang terintegrasi dalam proses pembelajaran dilaksanakan mulai dari tahap perencanaan, pelaksanaan, evaluasi.

Pelaksanaan pembelajaran finacial literaci memiliki indicator pembelajaran tematik, metode pembelajaran financial literasi, hasil penelitian dapat dilihat pada tabel 2 .

Tabel 2. Distribusi Frekuensi Pelaksanaan pembelajaran

\begin{tabular}{ccccccc}
\hline Indikator & \multicolumn{6}{c}{ Jawaban } \\
\cline { 2 - 7 } & 1 & $\%$ & 2 & $\%$ & 3 & $\%$ \\
\hline $\begin{array}{c}\text { Pembelajaran } \\
\text { Tematik }\end{array}$ & 50 & 17.4 & 118 & 41 & 104 & 36.1 \\
\hline Metode & 94 & 32 & 71 & 24.7 & 107 & 37.2 \\
$\begin{array}{c}\text { Pembelaj } \\
\text { Finacial Literaci }\end{array}$ & & & & & & \\
\hline
\end{tabular}

Penyampain pembelajaran finacial literasi sebagai sarana pembentukan karakter non konsumtif dan jiwa wirausaha disampaikan secara tematik, dari data 
diatas hanya $17,4 \%$ yang memasukan dalam semua muatan pembelajaran, $41 \%$ kadang-kadang memasukan pada muatan pembelajaran dan $36,1 \%$ tidak memasukan pada pembelajaran dengan alasan kesulitan dan terkejar target pembelajaran. Metode yang dipakai bervariasi dan menyenangkan hanya $32 \%$ yang melakukan, 24 kadang-kadang memakai metode bervariasi dan 37,2 tidak memakai metode yang bervariasi dalam pembelajaran. Penggunaan berbagai macam metode dalam pembelajaran mempengaruhi aktivitas atau perilaku siswa. Hal ini sejalan dengan penelitian Penelitian tersebut sejalan dengan penelitian yang dilakukan oleh Rhabeta Fiqri Fardian (2011) bahwa pengguanaan metode, dalam kegiatan pendahuluan dan proses pembelajaran telah mengembangkan nilai-nilai pendidikan karakter, terutama karakter bangsa yaitu berdoa dan bernyayi. Temuan ini senada disampaikan Lynn Revell dan James Arthur yang menyatakan pentingnnya tentang intervensi guru dalam bentuk bimbingan moral dan menentukan perilaku yang tepat dalam proses pembelajaran dan guru harus menjadi teladan untuk murid mereka

Evaluasi pembelajaran finacial literaci memiliki indikator penilaian otentik, yaitu dengan melakukan penilaian secara nyata sesuai aspek yang akan diukur baik dengan tes maupun lembar pengamatan, personil berkaitan dengan kemapuan guru, operasional, material finacial literaci yang mencakup 8 materi yaitu: 1) Kekayaanku; 2) Keinginan dan kebutuhan; 3) Mari berbelanja; 4) Mari berbagi; 5) Menabung; 6) Bekerja, membantu orang tua; 7). Bermain, membuat mainan; 8). Cita-citaku, merencanakan masa depan.

Tabel 3. Distribusi Frekuensi Evaluasi Pembelajaran

\begin{tabular}{ccccccc}
\hline Indikator & \multicolumn{6}{c}{ Jawaban } \\
\cline { 2 - 7 } & 1 & $\%$ & 2 & $\%$ & 3 & $\%$ \\
\hline $\begin{array}{c}\text { Penilaian } \\
\text { Otentik }\end{array}$ & 77 & 26.7 & 33 & 11.5 & 162 & 56.2 \\
\hline Personil & 88 & 30.6 & 65 & 22.6 & 119 & 41.3 \\
\hline Material & 34 & 11.8 & 118 & 41.0 & 120 & 41.7 \\
\hline Operasional & 0 & & 150 & 52.1 & 122 & 42.4 \\
\hline
\end{tabular}

Evaluasi pembelajaran yang dilakukan guru dengan penilaian outentik hanya 26,7 $\%$ dan materi finacial literasi hanya $11,8 \%$. Penilaian outentik sangat penting dilakuakan agar memperoleh penilaian secara utuh. Permasalahannya guru terkendala waktu dan kemampuan serta kemauan guru. Pada aspek evaluasi ini guru yang tidak melakukan penilaian outentik cukup tinggi. Pada hal hasil penelitian yang dilakukan Benning dkk (2003) menyimpulkan bahwa sekolah dengan implementasi pendidikan karakter yang tinggi, cenderung memiliki nilai akademik yang lebih tinggi dari tahun sebelum adanya implementasi pendidikan karakter.

Keberhasilan indikatornya pembelajaran adalah peningkatan kualitas karakter non konsumerisme dan karakter jiwa wirausaha, hasil olah data ditunjukkan pada tabel 4. 
Tabel 4. Distribusi Frekuensi Karakter Nonkunsumerisme dan Jiwa Wirausaha Indikator Jawaban

\begin{tabular}{ccccccc}
\cline { 2 - 7 } & 1 & $\%$ & 2 & $\%$ & 3 & $\%$ \\
\hline $\begin{array}{c}\text { Nonkunsumen } \\
\text { risme }\end{array}$ & 9 & 3.1 & 139 & 41 & 12 & 43. \\
& & & & & 4 & 1 \\
\hline Jiwa & 6 & 2.1 & 143 & 24. & 12 & 42. \\
Wirausaha & & & & 7 & 3 & 7
\end{tabular}

Pembelajaran finacial litersi menunjukan bahwa dapat menigkatkan karakter nonkonsumerisme $31 \%$, sedangkan untuk karakter jiwa wirausaha $21 \%$. Hal ini cukup baik karena penananaman karakter atau penginternalisasian nilai karakter nonkonsumerisme dan jiwa wirausaha dalam pembelajaran memerlukan kesabaran, pembiasaan dan pengulangan secara terus menerus.

Hasil perhitungan korelasi Kendalls, menyebutkan bahwa X1 (Perencanaan) pembelajaran financial literasi memiliki hubungan dengan Y (Kualitas karakter non konsumerisme dan Jiwa Usaha) sebesar 34 keeratannya, sedangkan variable X2 (Pelaksanaan) sebesar 0,98, dan terakhir X3 (Evaluasi) sebesar 173 dengan tarafsignifikansi $1 \%$ dengan derajat kepercayaan 99\%. Hal ini menunjukkan bahwa keeratan hubungan ketiga variable $\mathrm{x}$ dengan variable $\mathrm{y}$ cukup kuat dan memiliki kepercayaan yang tinggi.

Demikian juga dengan perhitungan hasil perhitungan korelasi Spearman, menyebutkan bahwa X1 (Perencanaan) pembelajaran financial literasi memiliki hubungan dengan Y (Kualitas pembentukan Karakter non konsumerisme dan Jiwa Usaha) sebesar 38 keeratannya, sedangkan variable X2 (Pelaksanaan) sebesar 108, dan terakhir X3 (Evaluasi) sebesar 189 dengan tarafsignifikansi $1 \%$ dengan derajat kepercayaan 99\%. Hal ini menunjukkan bahwa keeratan hubungan ketiga variable $\mathrm{X}$ dengan variable $\mathrm{Y}$ cukup kuat dan memiliki kepercayaan yang tinggi. Diantara keduanya hasil Spearman lebih tinggi. Dengan melihat keeratan hubungan tersebut maka dapat dikatakan bahwa hubungan Variabel menyakinkan sebagai kesatuan tindakan dalam mewujudkan karakter non konsumerime dan jiwa wirausaha yang memerlukan tiga variable independen yaitu perencanaan, pelaksanaan dan evaluasi

Hasil Uji Efektivitas, dari hasil analisa data maka dapat dikatakan bahwa unsur komponen yang dijadikan variable untuk melihat korelasi dan pengaruh menunjukan bahwa ketiga komponen perencanaan pembelajaran finacial literasi, pelaksanaan dan evaluasi pembelajaran finacial literasi memiliki hubungan yang kuat dan pengaruh pada keberhasilan pembelajaran karakter utamanya untuk membangun karakter non konsumerisme dan jiwa wirausaha.

Hasil perhitungan korelasi Kendalls menyebutkan bahwa perencanaan pembelajaran finacila literasi memiliki hubungan dengan kualitas pembentukan karakter nonkonsumerisme dan jiwa wirausaha (Y) sebesar 34,00. Sedangkan pelaksanaan pembelajaran $\left(\mathrm{X}_{2}\right)$ sebesar 0,98 dan evaluasi pembelajaran $\left(\mathrm{X}_{3}\right)$ sebesar 173 dengan taraf signifikansi 1\% dengan derajat kepercayaan 99\%. Hal ini menunjukan bahwa keeratan hubungan ketiga variabel dengan kualitas pembentukan karakter cukup kuat dan memiliki derajat kepercayaan tinggi.

Demikian juga dengan hasil perhitungan korelasi Spearman menunjukan bahwa perencanaan pembelajaran finacial litersi juga memiliki hubungan dengan kualitas pembelajaran karakter sebesar 38, sedangkan pelaksanaan pembelajaran 
sebesar 108 dan evaluasi pembelajaran sebesar 189 dengan taraf signifikansin $1 \%$ dengan derajat kepercayaan 99\%. Hal ini menunjukan bahwa keeratan hubungan ketiga variabel dengan pembentukan karakter cukup kuat dan memiki derajat kepercayaan cukup tinggi, walau hasil korelasi Sperman lebih tinggi. Hasil uji t dalam perhitungan menunjukkan nilai $\mathrm{X}_{1}$ sebesar 77.375, $\mathrm{X}_{2}$ sebesar $61.467, \mathrm{x}_{3}$ sebesar 173.000 dan dibanding kan dengan t table sebesar 57, 443 maka lebih besar, dengan demikian secara hipotetis dikatakan bahwa model pemelajaran yang dikembangkan dalam penelitian ini memiliki keefektifan.

\section{SIMPULAN}

Dari hasil analisa data sementara dapat disimpulkan bahwa (1). Model manajemen pembelajaran finacial literasi untuk membangun karakter nonkunsumerisme dan jiwa wirausaha cukup efektif berdasarkan hasil pengujian taraf signifikansi $1 \%$. Model mempunyai komponen perencanaan yang terdiri: identifikasi kebutuhan, perangkat pembelajaran, media dan bahan ajar. Proses tediri pelaksanaan dan evaluasi, output penelitian terbangunnya karakter nonkunsumerisme dan jiwawirausaha sehingga lebih meningkatkan kualitas pendidikan karakter.( 2) Komponen perencanaan pembelajaran, pelaksanaan pembelajaran dan evalauasi pembelajaran memiliki pengaruh terhadap keberhasilan pembentukan karakter non konsumerisme dan jiwa wirausaha secara signifikan. (3) Model manajemen pembelajaran finacial litersi untuk membangun karakter jiwawirausaha dan nonkonsumerisme dapat dikembangkan untuk menjadi bangunan teori yang memiliki kefektifan.

\section{DAFTAR RUJUKAN}

Abbeson, Adam. 2008. "Financial Literacy for Education" . Journal Financial \& Accounting, Emerald Group Publishing Limited 26/1 (2008) 35-46

ANZ; 2004. "Making a difference to financial literacy". Australia and New Zealand Banking Group Limited ABN 11005357522

Astuti, Danik. 2011. "Pembinaan Karakter pada Siswa Kelas VII di SMP Negeri 2 Secang Kabupaten Magelang”. Garuda: Referensi Ilmiah Indonesia.

Bogdan dan Taylor, 1975. "Creating competetive advantage through effective management education" Journal of Management Development Emerald Group Publishing Limited

Vol. 21 No. 9, 2002. pp. 241-250;

Benning dkk. 2003. "The Relationship of Character Education Implementation and Academik Achievment in Elementary Schools". Journal of Research in Character. Volume 1 Nomor 1

Bogdan, Robert C,, \& Sari Knopp Biklen, 1982. "Qualitative Research for education; An introduction to theory and Methods".Boston; Allyn and Bacon, Inc.

Cronbach, Lee, J. 1997. "Educational Psychology" (3 ${ }^{\text {rd }}$ edition, New York; Harcourt Brace Jovanovich, Inc. 
Cude, Brenda J et al. 2006. "College Students and Financial Literacy: What They Know and What We Need to Learn ". Eastern Family Economics and Resource Management Association

Fardian, Rhabeta Fiqri. 2011." Implementasi Pendidikan Berkarakter di SMA Negeri 3 Semarang”. Garuda, Referensi Ilmiah Indonesia"

Gall.M.D.,Gall.J.P. and Borg.W.R. 2003. "Educational Research. An Introduction" Seventh Edition. Boston: Allyn and Bacon

Guba, Egon G;\&Yvonna S. Lincoln.1981. "Effective Evaluation”. San Fransisco; Jossey - Bass Publisher.

Kholiq, Nur, 2012, "Pelaksanaan Pendidikan Karakter Secara Terintegrasi dalam KBM”.'http://nuansapendikar.blogspot.com/2012/01/blogpost_31.html diiunduh 2 Pebruari 2015

Johanssen, R. 1993. "System Modelling and Identification". New York: Prentice Hall International, Inc.

Lickona, Thomas. 1992. "Education for Character: How our Schools Teach Respect and Responsibility". New York Bantam Books Unblishing History.

Megawangi, Ratna, 2004. "Pendidikan Karakter. Solusi Yang Tepat Membangun Bangsa”. Jakarta, Star Energy (Kakap) Ltd.

Milles, M.B, \& Huberman, A.M 1984. “Analisis Data Kualitatif”; Terjemahan oleh Tjetjep Rohidi dan Mulyarto, Jakarta; Indonesia Press

Nurhadi, dkk. 2004. Pembelajaran Kontekstual dan Penerapannya Dalam KBK. Malang: UM Press

Racman, Maman, 2011. “Metode Penelitian Pendidikan Moral”. Semab rang, Unnes Press.

Senduk, Safir. 2001. "Mengelola Keuangan". Jakarta, Gramedia

Suharsimi, Arikunto \& Haryanto, 2002. "Model Evaluasi Program Pendikan”. Yogyakarta. FIP Universitas Negeri Yogyakarta

Suhertian, 1990. "Paradigma Pendidikan Universal di Era Modern dan Postmodern". Yogyakarta:Irci

Yu-Ting Chen, Daniel J. Walsh, 2008." Understanding, Experiencing, and Appreciating the Arts: Folk Pedagogy in Two Elementary Schools in Taiwan". International Journal of Education \& Seni, Volume 9 Nomor 610 Juni 2008. 